\title{
Experimental Study on Tensile Fatigue Strength of Steel Fiber Reinforced Concrete
}

\author{
Yang $\mathrm{Lu}^{1, \text { a }}$, Zhongren Feng ${ }^{2, \mathrm{~b}}$ \\ ${ }^{1,2}$ Department of Civil and Architecture Engineering, Wuhan University of Technology, Wuhan \\ 430000, PR China \\ a luyang17ce@163.com, bengz515@163.com
}

Keywords: steel fiber reinforced concrete; tensile fatigue strength; fatigue life equation Abstract. The tensile fatigue property of steel fiber reinforced concrete (SFRC) was studied. In an axial tensile fatigue experiment, 52 prismatic specimens were tested under various stress conditions. A significant increase is found in the fatigue life of SFRC comparing to that of ordinary concrete. The results also show that the fatigue lives of these specimens are in well agreement with Weibull distribution. Thus a series of fatigue life equations under different survival probabilities were established, as well as the ultimate fatigue strength equation containing two parameters - the ratios of maximum and minimum stress to tensile strength.

\section{Introduction}

Concrete structures such as crane girder, bridges, sleeper and cement concrete pavement usually bear long-term high-stress-amplitude repeated loads and are frequently subjected to fatigue failure, which has consumedly shortened those structures' service life. Therefore, the research and development on new kinds of concrete materials with high fatigue strength is of great importance to practical engineering.

Steel fiber reinforced concrete (SFRC) is a type of concrete reinforced by a certain amount of disorderly distributed steel fibers. With advantages like high-strength and good durability [1,2], it has become one of the directions of cement-based high-performance composite materials development. Since the crack-resist effect of steel fiber during the early age of concrete cracking has been proven to be remarkable [3], it is predicable that SFRC will be widely applied in structures bearing fatigue loads.

In this paper, an axial tensile fatigue experiment was conducted to study the tensile fatigue strength of SFRC, in which 52 prismatic specimens of size $100 \mathrm{~mm} * 100 \mathrm{~mm} * 300 \mathrm{~mm}$ were tested under various stress conditions. By analyzing data from the experiment, fatigue life equations corresponding to different survival probabilities were established, as well as the ultimate fatigue strength equation containing two parameters - the ratios of maximum and minimum stress to tensile strength.

\section{Experimental Programme}

Materials and Mix Proportion. An ordinary Portland cement 42.5R based on Chinese code was used. The fine aggregates were river sands. Rubble of size no greater than $20 \mathrm{~mm}$ was used as coarse aggregates. The wavy steel fibers, average length of $60 \mathrm{~mm}$, were made of cold-drawn steel. A plasticizer in 10\% water solution was used. The mix proportion is shown in Table 1.

To mix all the materials, firstly both fine and coarse aggregates as well as steel fibers were added into the concrete mixer and dry mixed for 2 minutes. Secondly, cement was put in and mixed for another 1 minute. Finally, water and plasticizer was added and mixed for 3 minutes. Then the mixture was poured into moulds and got vibrated on a vibrating table for 30 seconds.

Moulds and Specimens. One series of cubic specimens and two series of prismatic specimens were made and tested, as listed in Table 2. All the specimens were made with the same mixing proportion as given in Table 1. For moulds, series A used standard plastic cubic moulds while series $\mathrm{B}$ and $\mathrm{C}$ adopted customized composite board moulds. There were special brackets attached to the 
customized prismatic mould to fix ribbed steel bars, which were $14 \mathrm{~mm}$ in diameter, $14 \mathrm{~cm}$ in length, casted in both ends of the prismatic specimens by $6 \mathrm{~cm}$ as the tension transfer. The steel bars must be precisely axial and should be adjusted after casting and vibration. The specimens were cured outdoor under geotextiles for 28 days and watered once a day before tested.

Table 1 Mix proportion

\begin{tabular}{cccccc}
\hline Cement & Water & Sand & Rubble & Steel fiber & Plasticizer \\
\hline 528 & 175.5 & 667 & 1001 & 78.5 & 2.6 \\
\hline
\end{tabular}

Table 2 Size, quantity and usage of specimens

\begin{tabular}{c|ccc}
\hline Series & A & B & C \\
\hline Usage & Static compression test & Static tensile test & Fatigue test \\
Size $[\mathrm{mm}]$ & $150 * 150 * 150$ & $100 * 100 * 300$ & $100 * 100 * 300$ \\
Quantity & 9 & 3 & 52 \\
\hline
\end{tabular}

Static Tests. The average compressive strength-tested on specimens from series A-was 57.2MPa. Series B was used for static tensile test and the results are shown in Table 3.

Table 3 Results of static tensile test

\begin{tabular}{c|ccc}
\hline Specimen number & B1 & B2 & B3 \\
\hline Destructive tension $[\mathrm{kN}]$ & 27.21 & 27.05 & 28.34 \\
\hline Average destructive tension $[\mathrm{kN}]$ & \multicolumn{4}{|c}{27.53} \\
\hline Average tensile strength $[\mathrm{MPa}]$ & \multicolumn{4}{|c}{2.75} \\
\hline
\end{tabular}

Tensile Fatigue Test. The tensile fatigue test was conducted on electric servo-hydraulic material test system Instron1341 from the Material Research and Testing Center of Wuhan University of Technology (WUT). The value of constant-amplitude sinoidal repeated tensile-load applied in this test is determined by the average tensile strength obtained from the static tensile test described above. The specimens used in the fatigue test were from series $\mathrm{C}$ and were divided into 10 groups - Group $\mathrm{C} 1$ to Group $\mathrm{C} 10-$ depending on their stress conditions. The group division is shown in Table 4. $\mathrm{S}_{\max }$ and $S_{\min }$ stand for the ratios of maximum and minimum stress loaded in the test to the average tensile strength, respectively. If the number of fatigue load cycles to failure (i.e. fatigue life N) of two specimens from one group reached $10^{6}$, then fatigue damage is considered impossible to happen on SFRC under the corresponding stress condition.

Table 4 Stress conditions and group division of fatigue test

\begin{tabular}{c|cccccccccc}
\hline Group number & $\mathrm{C} 1$ & $\mathrm{C} 2$ & $\mathrm{C} 3$ & $\mathrm{C} 4$ & $\mathrm{C} 5$ & $\mathrm{C} 6$ & $\mathrm{C} 7$ & $\mathrm{C} 8$ & $\mathrm{C} 9$ & $\mathrm{C} 10$ \\
\hline $\mathrm{S}_{\max }$ & 0.73 & 0.75 & 0.78 & 0.8 & 0.85 & 0.73 & 0.75 & 0.78 & 0.8 & 0.85 \\
$\mathrm{~S}_{\min }$ & 0.1 & 0.1 & 0.1 & 0.1 & 0.1 & 0.2 & 0.2 & 0.2 & 0.2 & 0.2 \\
Loading frequency $\left[\mathrm{H}_{\mathrm{Z}}\right]$ & 15 & 15 & 10 & 10 & 10 & 15 & 15 & 10 & 10 & 10 \\
Quantity & 6 & 6 & 6 & 6 & 6 & 2 & 2 & 6 & 6 & 6 \\
\hline
\end{tabular}

\section{Analysis of the Fatigue Test}

Results. The fatigue lives of specimens from different stress conditions groups are shown in Table 5 . The randomness of these data is very obvious, so it's necessary to get the results statistically analyzed. 
Table 5 Results of fatigue test

\begin{tabular}{c|rrrrrr}
\hline Group number & \multicolumn{7}{|c}{ Fatigue life } \\
\hline C1 & 518373 & 589076 & 607363 & 623189 & 650174 & 684068 \\
C2 & 152381 & 179479 & 201637 & 251146 & 268894 & 302708 \\
C3 & 32976 & 42638 & 54891 & 65385 & 67821 & 96735 \\
C4 & 15332 & 17542 & 22933 & 25206 & 27164 & 30473 \\
C5 & 1346 & 1928 & 2215 & 2577 & 2817 & 3013 \\
C6 & 1000000 & 1000000 & & & & \\
C7 & 1000000 & 1000000 & & & & \\
C8 & 243413 & 271965 & 338287 & 355296 & 370810 & 413962 \\
C9 & 90226 & 113809 & 130757 & 150719 & 161825 & 179026 \\
C10 & 8694 & 11035 & 12463 & 12840 & 15977 & 16840 \\
\hline
\end{tabular}

Statistical Analysis of Results. According to the long-term practical experience, normal distribution theory is applicable for the situation of moderate fatigue life range (from ten thousand to one million in circulation), but Weibull distribution theory is not limited to this range thus be able to predict the safety life in high fatigue life range [4]. Therefore, statistical analysis in this article was conducted based on Weibull distribution theory.

Distribution regularities of fatigue life $\mathrm{N}$ under certain stress condition can be represented by Eq.1 [4], where $\mathrm{N}_{0}, \mathrm{~N}_{\mathrm{a}}$ and $\mathrm{b}$ stand for minimum fatigue life coefficient, fatigue life characteristic coefficient and Weibull shape coefficient, respectively.

$$
f(N)=\frac{b}{N_{a}-N_{0}}\left(\frac{N-N_{0}}{N_{a}-N_{0}}\right)^{b-1} \exp \left(-\left(\frac{N-N_{0}}{N_{a}-N_{0}}\right)^{b}\right) \quad\left(N_{0} \leq N<\infty\right)
$$

Let $\mathrm{N}_{0}=0$, then Eq.1 can be simplified into two-parameter Weibull frequency function as Eq.2.

$$
\mathrm{f}(\mathrm{N})=\mathrm{b} \frac{\mathrm{N}^{\mathrm{b}-1}}{\mathrm{~N}_{\mathrm{a}}^{\mathrm{b}}} e^{-\left(\frac{\mathrm{N}}{\mathrm{N}_{\mathrm{a}}}\right)^{\mathrm{b}}} \quad(0 \leq \mathrm{N}<\infty)
$$

The reliability p of Eq.2 can be represented by Eq.3.

$$
\mathrm{p}=e^{-\left(\frac{\mathrm{N}}{\mathrm{N}_{\mathrm{a}}}\right)^{\mathrm{b}}}
$$

Eq.4 can be transformed from Eq.3.

$$
\ln \mathrm{N}=\frac{1}{\mathrm{~b}} \ln \left(\ln \left(\frac{1}{\mathrm{p}}\right)\right)+\ln \mathrm{N}_{\mathrm{a}}
$$

Let $X=\ln (\ln (1 / p)), Y=\ln N$, then Eq.4 is transformed into Eq.5.

$$
\mathrm{Y}=\frac{\mathrm{X}}{\mathrm{b}}+\ln \mathrm{N}_{\mathrm{a}}
$$

A linear relationship is shown in Eq.5 between $\mathrm{X}$ and $\mathrm{Y}$, which forms the basis of testing whether the fatigue test data is in accordance with the Weibull distribution or not. The survival probabilities $\mathrm{p}$ can be calculated by Eq.6 [5], where $i$ and $p$ stand for the ordinal of data and the sample size, respectively.

$$
\mathrm{p}=1-\frac{\mathrm{i}}{\mathrm{K}+1}
$$


Table 6 gives an example of the testing process.

Table 6 Weibull distribution test for group C1

\begin{tabular}{c|cccccc}
\hline $\mathrm{i}$ & 1 & 2 & 3 & 4 & 5 & 6 \\
\hline $\mathrm{p}$ & 0.857 & 0.714 & 0.571 & 0.429 & 0.286 & 0.143 \\
$\mathrm{X}$ & -1.870 & -1.089 & -0.581 & -0.166 & 0.225 & 0.666 \\
$\mathrm{~N}$ & 518373 & 589076 & 607363 & 623189 & 650174 & 684068 \\
$\mathrm{Y}$ & 13.158 & 13.286 & 13.317 & 13.343 & 13.385 & 13.436 \\
\hline
\end{tabular}

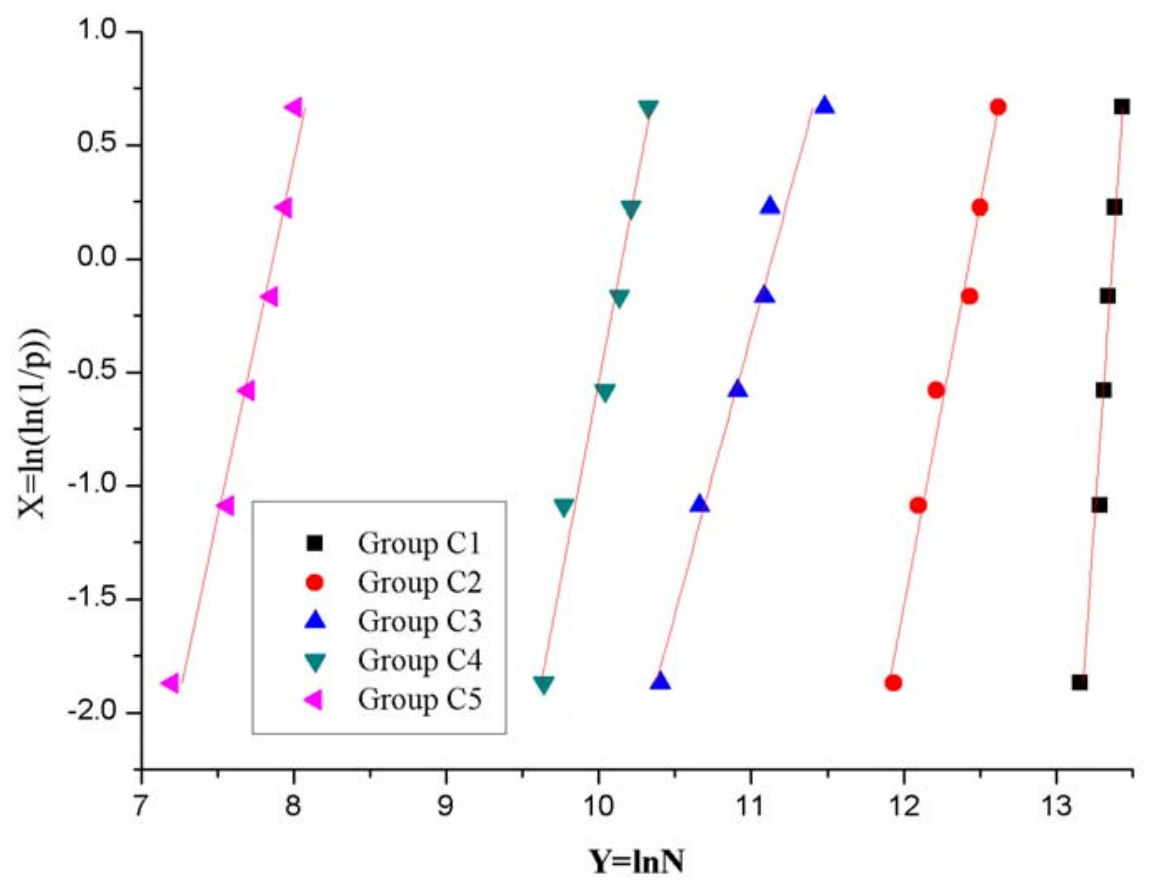

Fig.1 Weibull distribution test of group C1 to C5

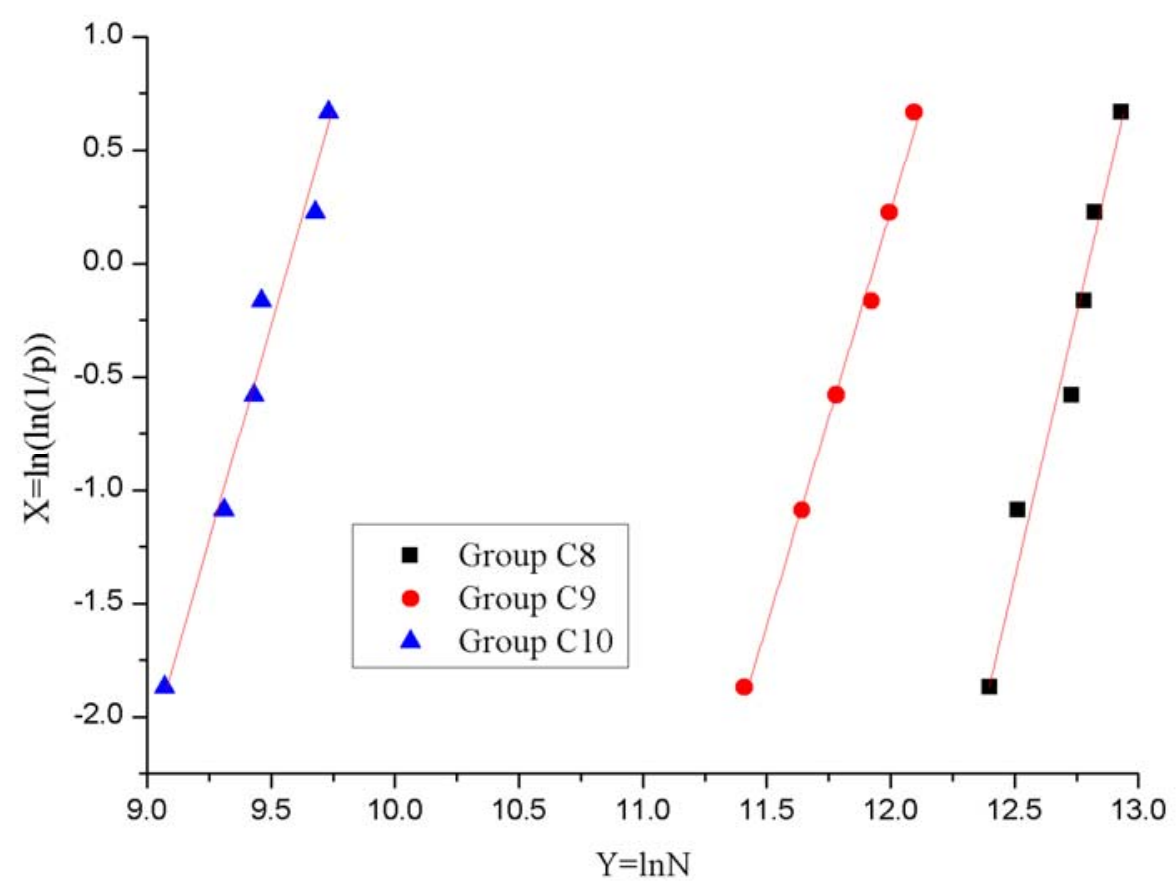

Fig.2 Weibull distribution test of group C8 to C10 
The testing results of group $\mathrm{C} 1$ to $\mathrm{C} 5$ and $\mathrm{C} 8$ to $\mathrm{C} 10$ as well as the corresponding fitting curves were drawn in two diagrams in which $\mathrm{Y}$ is the abscissa and $\mathrm{X}$ is the ordinate. The results are shown in Fig.1, Fig. 2 and Table 7. The correlation coefficient $r$ of the regression analysis are all greater than 0.95 , and the scatter diagrams also show a good linear relation among every group of data. Thus it can be concluded that the testing results are in accordance with the Weibull distribution.

Table 7 Weibull distribution test results

\begin{tabular}{c|cccc}
\hline Group & $1 / \mathrm{b}$ & $\operatorname{lnN}_{\mathrm{a}}$ & $\mathrm{N}_{\mathrm{a}}$ & $\mathrm{r}$ \\
\hline $\mathrm{C} 1$ & 0.102 & 13.369 & 639684 & 0.9617 \\
$\mathrm{C} 2$ & 0.282 & 12.433 & 250918 & 0.9749 \\
$\mathrm{C} 3$ & 0.406 & 11.135 & 68549 & 0.9679 \\
$\mathrm{C} 4$ & 0.284 & 10.153 & 25672 & 0.9670 \\
$\mathrm{C} 5$ & 0.319 & 7.863 & 2599 & 0.9632 \\
$\mathrm{C} 8$ & 0.214 & 12.798 & 361494 & 0.9569 \\
$\mathrm{C} 9$ & 0.273 & 11.936 & 152643 & 0.9928 \\
$\mathrm{C} 10$ & 0.261 & 9.569 & 14319 & 0.9667 \\
\hline
\end{tabular}

Tensile p-S-N Equations. The specification system of our country is built on the basis of strength reliability and failure probability, thus a series of tensile fatigue life curves corresponding to specified survival probability would be more significant to practical design and production than a general one. Based on the results in section 3.2, linear regression was done on the data of fatigue lives with the same survival probability from different groups, then the SFRC tensile fatigue life equations corresponding to specified survival probability, i.e. the tensile p-S-N equations of SFRC, were established [4,6].

Eq.7 can be transformed from Eq.3.

$$
\mathrm{N}=\mathrm{N}_{\mathrm{a}}(-\ln \mathrm{p})^{\frac{1}{\mathrm{~b}}}
$$

Substituting value of $1 / \mathrm{b}$ and $\mathrm{N}_{\mathrm{a}}$ from table 7 into Eq. 7 gives the results shown in table 8 .

Table 8 Fatigue life corresponding to specified survival probability

\begin{tabular}{c|ccccc}
\hline \multirow{2}{*}{ Group } & \multicolumn{5}{|c}{$\mathrm{p}$} \\
\cline { 2 - 6 } & 0.95 & 0.9 & 0.8 & 0.7 & 0.5 \\
\hline C1 & 472363 & 508383 & 548861 & 575781 & 616191 \\
C2 & 108456 & 132903 & 164275 & 187540 & 226246 \\
C3 & 20531 & 27498 & 37290 & 45109 & 59074 \\
C4 & 11042 & 13547 & 16766 & 19155 & 23133 \\
C5 & 1008 & 1268 & 1611 & 1871 & 2313 \\
C8 & 191347 & 223243 & 262169 & 289872 & 334202 \\
C9 & 67794 & 82531 & 101315 & 115168 & 138096 \\
C10 & 6589 & 7953 & 9676 & 10937 & 13011 \\
\hline
\end{tabular}

The fitting curves of data from each column of table 8 can be expressed as Eq.8, and the corresponding coefficients are shown in table 9 . The value of linear regression correlation parameter Adj. R-Square are all greater than 0.98 , which shows that the equation is a good description of tensile fatigue property of SFRC.

$$
\lg \mathrm{N}=\mathrm{A}+\mathrm{B} * \mathrm{~S}_{\max }+\mathrm{C} * \mathrm{~S}_{\min }
$$


Table 9 Coefficients of $\mathrm{p}-\mathrm{S}-\mathrm{N}$ equation

\begin{tabular}{c|cccc}
\hline $\mathrm{p}$ & $\mathrm{A}$ & $\mathrm{B}$ & $\mathrm{C}$ & Adj. R-Square \\
\hline 0.95 & 20.35 & -21.44 & 8.30 & 0.9867 \\
0.9 & 20.17 & -21.08 & 8.11 & 0.9925 \\
0.8 & 19.99 & -20.71 & 7.91 & 0.9969 \\
0.7 & 19.88 & -20.47 & 7.79 & 0.9986 \\
0.5 & 19.72 & -20.14 & 7.61 & 0.9998 \\
\hline
\end{tabular}

For instance, let survival probability $\mathrm{p}=0.5$, then the corresponding $\mathrm{p}-\mathrm{S}-\mathrm{N}$ equation of SFRC can be expressed as Eq.9.

$$
\lg \mathrm{N}=19.72-20.14 * \mathrm{~S}_{\max }+7.61 * \mathrm{~S}_{\min }
$$

Compared with tensile fatigue test results of plain concrete at home and abroad [7-9], the absolute value of the p-S-N curve coefficients obtained in this test is bigger, which indicates that SFRC is more sensitive to stress amplitude. Besides, SFRC's tensile fatigue life under all kinds of stress conditions, especially the conditions of lower stress amplitude, is apparently higher than plain concrete, which shows a pretty nice tensile fatigue performance of SFRC.

Ultimate Fatigue Strength Equation. Let $\mathrm{N}=10^{6}$ be the threshold of infinite fatigue life, and let $\mathrm{p}=0.5$, then the ultimate strength equation can be expressed by Eq.10. That is, when the stress ratio values are in the region given by Eq.11, SFRC won't fail of tensile fatigue. That region is also shown in Fig. 3 as the area between two curves and filled with dotted lines.

$$
\begin{gathered}
20.14 * S_{\max }-7.61 * S_{\min }=13.72 \\
\left\{\begin{array}{c}
20.14 * S_{\max }-7.61 * S_{\min } \leq 13.72 \\
S_{\min } \leq S_{\max }
\end{array}\right.
\end{gathered}
$$

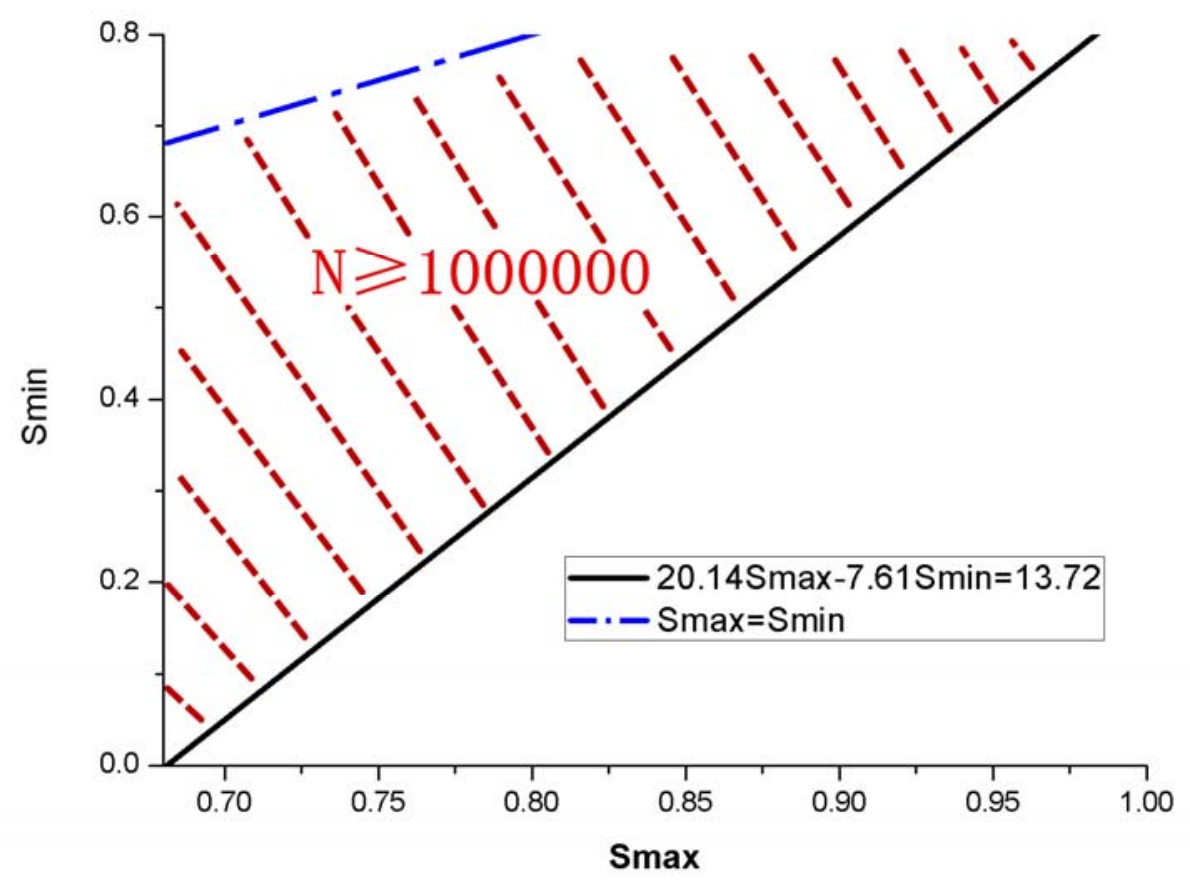

Fig.3 The ultimate strength curve and infinite fatigue life region of SFRC 


\section{Summary}

1) Fatigue life of SFRC is in well agreement with the simplified Weibull distribution.

2) The p-S-N equation of SFRC can be expressed as Eq.8, in which the coefficients corresponding to different survival probabilities can apply those given in this paper.

$\lg \mathrm{N}=\mathrm{A}+\mathrm{B} * \mathrm{~S}_{\max }+\mathrm{C} * \mathrm{~S}_{\min }$

3) The ultimate fatigue strength equation of SFRC is a linear equation containing two parameters - the ratios of maximum and minimum stress to tensile strength. When those two parameters are within the range given by Eq.11, SFRC won't fail of tensile fatigue.

$\left\{\begin{array}{c}20.14 * \mathrm{~S}_{\max }-7.61 * \mathrm{~S}_{\min } \leq 13.72 \\ \mathrm{~S}_{\min } \leq \mathrm{S}_{\max }\end{array}\right.$

4) SFRC's tensile fatigue life under all kinds of stress conditions is apparently higher than that of plain concrete, which shows a pretty nice tensile fatigue performance of SFRC.

\section{Acknowledgements}

This work was financially supported by the Fundamental Research Funds for the Central Universities (2015-zy-062).

\section{References}

[1] Kittinun Sirijaroonchai, Sherif El-Tawil and Gustavo Parra-Montesinos: Cement and Concrete Composites Vol. 32 (2009), p.66-72.

[2] K.Wille, S.El-Tawil and A.E. Naaman: Cement and Concrete Composites Vol. 48 (2014), p.53-66.

[3] Jianming gao, Wei Sun: China Concrete and Cement Products Vol. 1 (1989), p.10-12. (In Chinese)

[4] Zhentong Gao: Applied Statistics in Fatigue (National Defence Industry Press, Beijing, 1986). (In Chinese)

[5] Ziruo Yu, Mingzhe An and Guiping Yan: Concrete Vol. 225 (2008), p.3-6. (In Chinese)

[6] J.J.Xiong, R.A.Shenoi: International Journal of Fracture Vol. 145 (2007), p.273-283.

[7] Guangyi Zhao, Peigang Wu and Weiwei Zhan: China Civil Engineering Journal Vol. 06 (1993), p.13-19. (In Chinese)

[8] Cornelissen.H.A.W, Reinhardt.H.W: Mag. Of Concrete Research Vol. 36 (1984), p.216-227.

[9] Yupu Song: Fatigue Behavior and Design Principle of Concrete Structures (China Machine Press, Beijing, 2006). (In Chinese) 